\title{
Use of Milrinone in Critically III Children
}

\author{
Teresa Bishara, Winnie T W Seto, Angela Trope, and Christopher S Parshuram
}

\begin{abstract}
Background: Optimal dose adjustment of milrinone in critically ill children is challenging because of conflicting information about the association between dose and outcomes in this age group.

Objectives: To describe the use of milrinone in critically ill children and to explore associations between milrinone dosing and clinical outcomes, specifically effectiveness and adverse events.
\end{abstract}

Methods: This retrospective cohort study was performed in a consecutive sample of children admitted to a university-affiliated critical care unit (January to June 2004). The relations between milrinone dosing and its effectiveness (based on prevention of low cardiac output syndrome, defined as a difference in oxygen saturation between arterial and mixed venous blood of at least $30 \%$ or an increase in serum lactate $>2 \mathrm{mmol} / \mathrm{L}$ ) and its adverse effects (thrombocytopenia, arrhythmia) were evaluated by logistic regression.

Results: A total of 197 children from 213 admissions (ranging in age from newborn to 18 years) were included in the study. Milrinone was initiated with a median loading dose of $99.2 \mu \mathrm{g} / \mathrm{kg}$ (range 22.1-162.2 $\mu \mathrm{g} / \mathrm{kg}$ ). The initial loading dose was higher if given in the operating room rather than the Critical Care Unit (median 99.7 versus $51.0 \mu \mathrm{g} / \mathrm{kg}$; $p<0.001$ ). Subsequent loading doses, for patients who received them, were lower (median $49 \mu \mathrm{g} / \mathrm{kg}$ ). Milrinone was infused at a median rate of $0.64 \mu \mathrm{g} / \mathrm{kg}$ per minute (range $0.13-2.08 \mu \mathrm{g} / \mathrm{kg}$ per minute) for a median of $43.1 \mathrm{~h}$. There was no relation between serum creatinine level and the maintenance dose of milrinone $\left(r^{2} \leq 0.0335\right)$. Low cardiac output syndrome was relatively frequent (166 [77.9\%] of the 213 admissions). There was a trend for occurrence of this syndrome in patients with greater average milrinone dose rate (odds ratio [OR] 8.21, $95 \%$ confidence interval $[\mathrm{CI}] 0.98-69.15, p=0.053)$ and with longer duration of milrinone therapy (OR 1.01, 95\% CI 1.01-1.02, $p<0.05$ ). Adverse events were relatively frequent (thrombocytopenia for 27 admissions [12.7\%], arrhythmia for 82 admissions [38.5\%]) but were not significantly associated with milrinone dosing.

Conclusions: A retrospective evaluation of milrinone use in critically ill children revealed variable utilization and frequent occurrence of both low cardiac output syndrome and adverse events. Further prospective research is needed to understand the impact of individual pharmacokinetic differences on pharmacodynamic responses, to guide optimal dose adjustment, improve outcomes, and minimize toxic effects.

Key words: milrinone, drug utilization review, pediatrics, low cardiac output, arrhythmia, thrombocytopenia

\section{RÉSUMÉ}

Contexte : L'ajustement optimal de la posologie de milrinone chez les enfants gravement malades est délicat, à cause de l'information contradictoire sur le lien entre la dose et les résultats cliniques dans cette population.

Objectifs : Décrire l'utilisation de la milrinone chez les enfants gravement malades et examiner les liens entre la dose de milrinone et les résultats cliniques, plus particulièrement l'efficacité et les effets indésirables.

Méthodes : On a mené une étude de cohorte rétrospective chez un échantillon d'enfants admis consécutivement dans une unité de soins intensifs affiliée à une université entre janvier et juin 2004. Les liens entre la dose de milrinone et son efficacité (objectivée par la prévention d'un syndrome de bas débit cardiaque, défini comme une différence de saturation en oxygène entre le sang artériel et le sang veineux mêlé d'au moins 30 $\%$ ou une augmentation du taux de lactate sérique supérieure à 2 $\mathrm{mmol} / \mathrm{L}$ ) et ses effets indésirables (c.-à-d. thrombocytopénie et arythmie) ont été évalués au moyen d'une analyse de régression logistique.

Résultats : Un total de 197 enfants, âgés de la naissance à 18 ans, ont été admis à l'étude au cours de 213 hospitalisations durant la période visée. Le traitement par la milrinone a été amorcé par une dose de charge médiane de $99,2 \mu \mathrm{g} / \mathrm{kg}$ (plage de 22,1 à 162,2 $\mu \mathrm{g} / \mathrm{kg}$ ). La dose de charge initiale était plus élevée lorsqu'elle était administrée en salle d'opération plutôt qu'à l'unité de soins intensifs (dose médiane de 99,7 contre 51,0 $\mu \mathrm{g} / \mathrm{kg}$; $p<0,001$ ). Certains patients ont reçu des doses de charge subséquentes qui étaient toutefois moins élevées (dose médiane de $49 \mu \mathrm{g} / \mathrm{kg}$ ). La milrinone était perfusée à un débit médian de $0,64 \mu \mathrm{g} / \mathrm{kg}$ par minute (plage de 0,13 à $2,08 \mu \mathrm{g} / \mathrm{kg}$ par minute) pendant une durée médiane de 43,1 heures. On n'a observé aucun lien entre la créatininémie et la dose d'entretien de milrinone $\left(r^{2} \leq 0,0335\right)$. Lapparition d'un syndrome de bas débit cardiaque était relativement fréquente (166 [77,9\%] des 213 hospitalisations). On a observé que ce syndrome avait tendance à se manifester chez les patients dont le débit de perfusion moyen de milrinone était plus élevé (risque relatif approché [RRA] de 8,21, intervalle de confiance [IC] à $95 \%$ de $0,98-69,15, p=0,053)$ et la durée de traitement par la milrinone était plus longue (RRA de 1,01, IC à $95 \%$ de $1,01-1,02, p<0,05)$. Les effets indésirables étaient relativement fréquents (une thrombocytopénie s'étant manifesté durant 27 hospitalisations [12,7 \%] et une arythmie durant 82 hospitalisations $[38,5 \%])$, mais sans association significative à la dose de milrinone.

Conclusions : L'analyse rétrospective de l'administration de milrinone chez les enfants gravement malades a révélé des habitudes d'utilisation variable de ce médicament et la survenue fréquente du syndrome de bas débit cardiaque et d'effets indésirables. Des études prospectives sont nécessaires pour comprendre l'effet des différences de comportement pharmacocinétique sur les réponses pharmacodynamiques chez un patient, pour guider l'ajustement optimal de la dose, améliorer les résultats et minimiser les effets toxiques.

Mots clés : milrinone, évaluation de l'utilisation des médicaments, pédiatrie, bas débit cardiaque, arythmie, thrombocytopénie

[Traduction par l'éditeur] 


\section{INTRODUCTION}

$\mathrm{M}$

ilrinone is a potent selective inhibitor of type III phosphodiesterase. It is used to improve cardiac output by inotropic effect and reduction of afterload. In addition, milrinone may improve myocardial relaxation between contractions. ${ }^{1}$ Milrinone is used as a first-line agent for children who have undergone cardiac surgery for prevention of low cardiac output syndrome $e^{2-5}$ and as second-line therapy for children with vasoconstriction septic shock. ${ }^{6}$

A clear relationship between the dose or plasma concentration of milrinone and its efficacy or toxicity in children has yet to be defined, because of limitations and inconsistencies in the existing pharmacokinetic literature. ${ }^{2,3,5,7-10}$ The adverse effects of milrinone include sinus tachycardia, arrhythmia, ${ }^{1}$ hypotension requiring vasopressor therapy, ${ }^{11,12}$ gastrointestinal upset (feed intolerance, bleeding, vomiting, and diarrhea), and central nervous system disturbance (agitation and seizures). The half-life of milrinone was about $2 \mathrm{~h}$ in healthy adult volunteers ${ }^{1,13,14}$ but was prolonged in patients with renal impairment, ${ }^{1,15}$ in infants younger than 1 year, ${ }^{2}$ and in neonates. ${ }^{3,10,16}$ Dose adjustment is recommended for these groups. ${ }^{1,16}$

At The Hospital for Sick Children in Toronto, Ontario, the loading dose for milrinone (at the time of study) was 50 $\mu \mathrm{g} / \mathrm{kg}$, and 3 options were available for maintenance therapy: $0.33,0.66$, and $0.99 \mu \mathrm{g} / \mathrm{kg}$ per minute. No modifications were recommended to address patient-specific factors such as age or renal function. In the literature, the dosing recommendations for children include initial loading dose of $50 \mu \mathrm{g} / \mathrm{kg}^{3,8}$ to 75 $\mu \mathrm{g} / \mathrm{kg},{ }^{5,716}$ followed by infusion at a rate of $0.5 \mu \mathrm{g} / \mathrm{kg}$ per minute ${ }^{2,8}$ up to $1 \mu \mathrm{g} / \mathrm{kg}$ per minute. ${ }^{7}$

Given the vulnerability of the population requiring milrinone and the frequency of renal dysfunction in critically ill children, ${ }^{17,18}$ this study was performed to determine dosing practices for and clinical outcomes of children receiving milrinone. The primary objective was to describe milrinone use in critically ill children. The secondary objective was to explore the association between milrinone dosing and the proportion of patients experiencing low cardiac output syndrome (despite milrinone therapy) or adverse drug-related events.

\section{METHODS}

A retrospective evaluation was performed in a cohort of consecutive patients. Patients admitted to the pediatric Critical Care Unit (CCU) of The Hospital for Sick Children starting in January 2004 who received milrinone intravenously were eligible for inclusion. There were no exclusion criteria, which allowed patients with a variety of indications to be included in the analysis. Patients receiving milrinone were identified through the electronic patient database of the CCU.
To determine milrinone dosing practices, several characteristics of milrinone therapy were abstracted from the patients' charts: loading dose, maintenance infusion rate, tapering regimen, interruptions, and overall duration of therapy. Loading doses given immediately postoperatively were included, to capture as many patients as possible. Patients who received milrinone before admission to the CCU were captured by means of medication lists from anesthesiology records, transfer letters, or pharmacy records. Children whose milrinone infusion was stopped and restarted were considered to have had an interruption in their therapy; the total duration of milrinone therapy was calculated as the sum of all infusions. Concomitant medications for circulatory support, as well as anti-arrhythmics, antihypertensives, potential nephrotoxins, anticoagulants, and "platelet-lowering" drugs, were also recorded. All doses were expressed on a per-kilogram basis. Death in the CCU and various patient characteristics (age, weight, sex, diagnosis, type of surgery, duration of use of aortic clamp, duration of cardiopulmonary bypass, length of stay, renal function, and other laboratory data) were recorded to capture factors potentially associated with development of low cardiac output syndrome, thrombocytopenia, or arrhythmia.

The clinical outcomes were effectiveness, assessed in terms of prevention of low cardiac output syndrome, and development of adverse events (specifically, thrombocytopenia and arrhythmia). Outcomes were defined on the basis of the literature review, as well as consensus among the clinical investigators and staff intensivists. Low cardiac output syndrome was defined as a difference in oxygen saturation between arterial and mixed venous blood $\left(\mathrm{AVO}_{2}\right)$ of at least $30 \%$ or an increase in serum lactate of more than $2 \mathrm{mmol} / \mathrm{L}$. ${ }^{5}$ Thrombocytopenia was defined as a platelet count of less than $50 \times 10^{9} / \mathrm{L}$. The occurrence and type of arrhythmia were determined by an electrophysiologist, who reviewed the chart notes and electrocardiograms. Renal dysfunction was defined using the age-specific criteria of the pediatric logistic organ dysfunction score. ${ }^{17}$

A sample size of 200 patients was chosen to support multiple regression with up to 10 potentially predictive variables and to provide reasonably precise estimates of the rates of low cardiac output syndrome and potentially adverse events. ${ }^{19}$

\section{Statistical Analysis}

Descriptive data were summarized as means, standard deviations, and medians for continuous variables and proportions for categorical variables. Univariate analysis between categorical independent variables and each outcome was performed by means of $2 \times 2$ contingency tables. Variables having statistically significant correlation with the outcomes $(p<0.05)$ according to the Fisher exact test were included in the regression analysis. Univariate analysis between continuous independent variables 
and each outcome was described by correlation coefficients. The selection of variables for inclusion in the initial regression model was based on the following criteria: measurements for a particular variable were available for more than $80 \%$ of the patients, there was a statistically significant correlation with the outcomes ( 2 -tailed $p<0.20$ ), and the variable was not highly correlated with other variables. If independent variables were highly correlated (i.e., Pearson correlation coefficient > 0.8), only one of the correlated variables was included in the regression model, on the basis of biological plausibility and smallest $p$ value.

Multiple logistic regression was used to assess the strength of independent associations between the independent variables (milrinone dosing, patient characteristics) and the dependent or outcome variables (development of low cardiac output syndrome, arrhythmia, or thrombocytopenia). A stepwise backward method was used as the primary variable-selection technique for multiple logistic regression, beginning with all eligible variables. Appendix 1 (see www.cjhp-online.ca/ index.php/cjhp/issue/view/78) lists the variables entered into the multiple logistic regression. Milrinone dosing variables were retained in all of the regression models to assess their associations with outcome variables. The choice of a final logistic regression model containing independent variables was based on the $C$ index (where a larger number, approaching 1, indicates greater accuracy of the chosen model) and the Hosmer-Lemeshow test (where a smaller $p$ value indicates lack of goodness of fit).

Data were abstracted into a customized database (Access, Microsoft). Data manipulation and statistical analyses were performed with SPSS 13.0 for Windows (SPSS Inc, Somers, New York), SAS 9.1 for Windows (SAS Inc, Carey, North Carolina), and Excel (Microsoft). The study protocol was approved by the Research and Ethics Board at The Hospital for Sick Children.

\section{RESULTS}

A total of 202 potentially eligible patients were identified. Of these, 197 received milrinone in the CCU between January 5 and June 19, 2004; an additional 5 patients who had received milrinone in the operating room but not the CCU were excluded from the study (Figure 1). Of the patients included in the study, 12 were admitted twice and 2 were admitted 3 times, for a total of 213 admissions. Most of the admissions (202 [94.8\%]) were for cardiac disease, $5(2.3 \%)$ were for sepsis, and $6(2.8 \%)$ were for other medicosurgical diseases or conditions (Table 1). Serum creatinine values were available for 189 $(88.7 \%)$ of the admissions. For 27 of these admissions, the patient had high creatinine on the first day in the CCU and 66 had elevated creatinine during therapy.

\section{Dosing Practices for Milrinone Loading Doses}

Milrinone therapy was started with a median loading dose of $99.2 \mu \mathrm{g} / \mathrm{kg}$ (range $22.1-162.2 \mu \mathrm{g} / \mathrm{kg}$ ). Subsequent loading doses, for those who received them, were lower (median 49 $\mu \mathrm{g} / \mathrm{kg}$ for the second to fifth loading doses) (Table 2). A total of 251 loading doses of milrinone were administered in 196 $(92.0 \%)$ of the 213 admissions; just one loading dose was administered in $151(70.9 \%)$ of the admissions. For 171 $(80.3 \%)$ of the admissions, the initial loading dose was administered in the operating room. The median initial loading dose was higher if given in the operating room than if given in the CCU (median $99.7 \mu \mathrm{g} / \mathrm{kg}$ versus $51.0 \mu \mathrm{g} / \mathrm{kg}$; $p<0.001$ by Mann-Whitney-Wilcoxon test).

\section{Maintenance Infusion and Dose Adjustments}

The median duration of milrinone infusions was $43.1 \mathrm{~h}$ (range $0.5-928.6 \mathrm{~h}$ ), with the median length of stay being 3 days (range 0.4-184 days). In 159 (74.6\%) of the 213

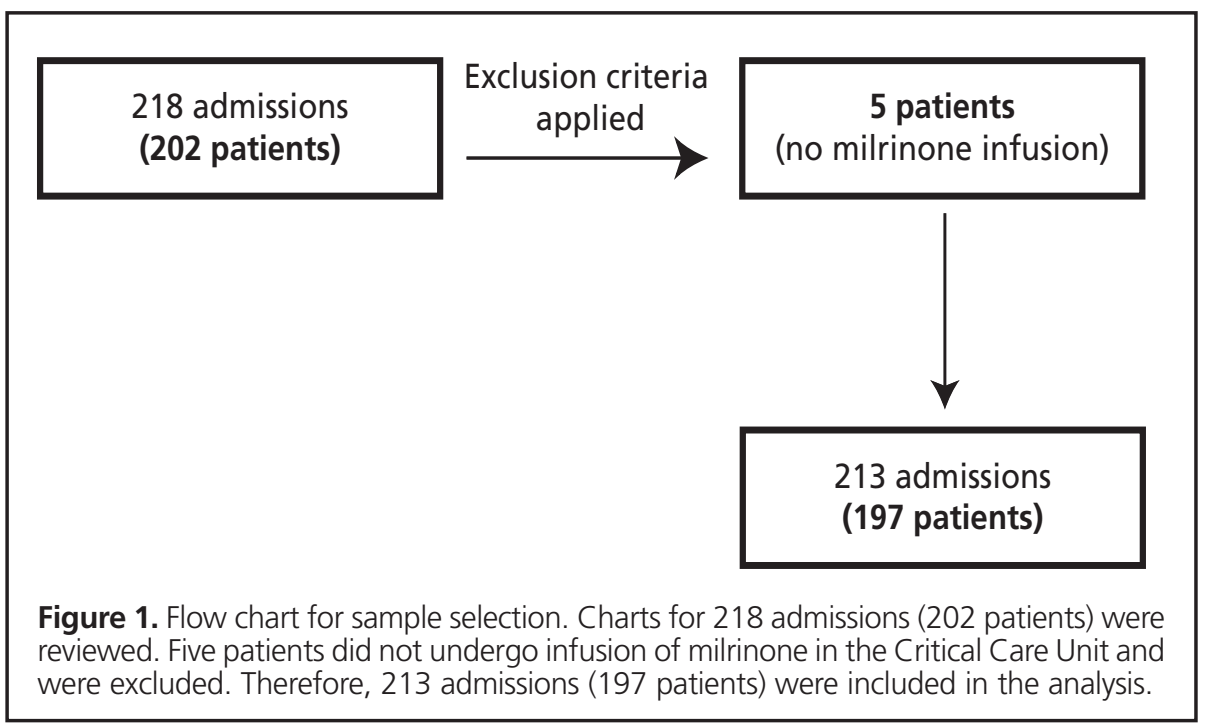


Table 1. Patient Characteristics and Outcomes for a Study of Milrinone Use in Critically III Children

\begin{tabular}{|c|c|c|}
\hline Characteristic & No. of Admissions* & Mean \pm SD or No. $(\%)$ \\
\hline $\begin{array}{l}\text { Weight (kg) } \\
\text { Median (range) }\end{array}$ & 213 & $\begin{array}{c}11.3 \pm 14.4 \\
6.4(2.0-84.2)\end{array}$ \\
\hline Age (months) & 213 & $28.7 \pm 49.4$ \\
\hline Median (range) & & $6.1(<1$ to 221.0$)$ \\
\hline Length of stay (days) & 213 & $8.2 \pm 18.7$ \\
\hline Median (range) & & $3.0(0.4-184.0)$ \\
\hline Sex & 213 & \\
\hline Male & & $101(47.4)$ \\
\hline Female & & $112(52.6)$ \\
\hline Premature birth & 213 & $3 \quad(1.4)$ \\
\hline \multicolumn{3}{|l|}{ Admission diagnosist } \\
\hline Cardiac & 213 & $202(94.8)$ \\
\hline Nonsurgical & 202 & $11(5.4)$ \\
\hline Biventricular repair & 202 & $151(74.8)$ \\
\hline Single ventricle repair & 202 & 40 (19.8) \\
\hline Medicosurgical & 213 & $11 \quad(5.2)$ \\
\hline Sepsis & 11 & $5(45)$ \\
\hline Other & 11 & $6(55)$ \\
\hline \multicolumn{3}{|l|}{ Renal function } \\
\hline High creatinine for age $\neq$ & 189 & $66(34.9)$ \\
\hline High creatinine for age on day $1 \S$ & 188 & $27(14.4)$ \\
\hline \multicolumn{3}{|l|}{ Outcomes } \\
\hline $\mathrm{AVO}_{2}$ difference $\geq 30 \%$ & 213 & $162(76.1)$ \\
\hline Lactate difference $>2 \mathrm{mmol} / \mathrm{L}$ & 190 & $29(15.3)$ \\
\hline Arrhythmia & 213 & $82(38.5)$ \\
\hline Platelet count $<50 \times 10^{9} / \mathrm{L}$ & 213 & $27(12.7)$ \\
\hline Death & 197 & $12(6.1)$ \\
\hline \multicolumn{3}{|c|}{$\begin{array}{l}\mathrm{AVO}_{2}=\text { arterial mixed venous oxygen saturation, } \mathrm{SD}=\text { standard deviation. } \\
\text { *Number of admissions for which data were available, except as indicated otherwise. } \\
\text { †Percentages for subcategories are based on the number in each category. } \\
\text { †During milrinone therapy. } \\
\S \text { Day } 1 \text { is day of admission to Critical Care Unit. }\end{array}$} \\
\hline
\end{tabular}

admissions, the patient completed 3 or fewer days of milrinone therapy. The median dose rate was $0.64 \mu \mathrm{g} / \mathrm{kg}$ per minute. For most of the admissions (197 [92.5\%]), the patients did not experience an interruption in the milrinone infusion. Dose tapering at the end of milrinone therapy was performed for 70 (32.9\%) of the 213 admissions.

There was no relationship between the milrinone infusion rate and serum creatinine level for children in any age group (Figure 2).

\section{Concomitant Medications}

The most commonly used vasoactive drugs were dopamine (94 admissions [44.1\%]) and epinephrine (32 [15.0\%]), followed by vasopressin (22 [10.3\%]) and phenoxybenzamine (13 [6.1\%). Nephrotoxic medications (including aminoglycosides, vancomycin, acyclovir, ganciclovir, amphotericin, cidofovir, cyclosporine, tacrolimus, and sirolimus) were used in $58(27.2 \%)$ of the admissions. Anticoagulants and platelet-lowering drugs (unfractionated heparin, lowmolecular-weight heparin, warfarin) were used in less than $10 \%$ of admissions (21 and 22 admissions, respectively).

\section{Clinical Outcomes}

Low cardiac output syndrome was observed in 166 (77.9\%) of the admissions. In 162 admissions, the patient had an $\mathrm{AVO}_{2}$ difference greater than 30\%, and in 29 admissions there was an increase in lactate greater than $2 \mathrm{mmol} / \mathrm{L}$ (Table 1 ). In 25 of these admissions, (11.7\% of the total), both criteria were recorded. Arrhythmia during milrinone use was documented in $82(38.5 \%)$ of the admissions and thrombocytopenia in 27 (12.7\%) (Table 1).

\section{Factors Independently Associated with Outcomes}

Stepwise backward regression showed that 3 milrinonerelated factors were independently associated with outcomes. First, there was a trend toward an association between higher average dose rate and low cardiac output syndrome $(p=0.053)$. Second, longer duration of milrinone therapy was associated with low cardiac output syndrome $(p<0.001)$. However, no statistically signficiant association was found between milrinione dosing and thrombocytopenia or arrhythmias (Table 3). None of the interaction terms tested was significant. 


\section{Table 2. Milrinone Dosing Characteristics}

\begin{tabular}{|c|c|c|c|}
\hline Dosing Parameter & $\begin{array}{l}n / N^{*} \text { or No. } \\
\text { of Admissions }\end{array}$ & Mean \pm SD or No. $(\%)$ & Median (Range) \\
\hline \multicolumn{4}{|l|}{ Loading dose } \\
\hline Cumulative loading dose $(\mu \mathrm{g} / \mathrm{kg})$ & $196 / 213$ & $95.4 \pm 53.5$ & $99.3(0-313.4)$ \\
\hline No. of admissions with loading dose & $196 / 213$ & $1.2 \pm 0.8$ & $1(0-5)$ \\
\hline \multicolumn{4}{|l|}{ Location of administration } \\
\hline Operating room & $175 / 213$ & $0.8 \pm 0.4$ & $1(0-2)$ \\
\hline CCU & $88 / 213$ & $0.4 \pm 0.8$ & $0(0-4)$ \\
\hline \multicolumn{4}{|l|}{ Size of loading dose $(\mu \mathrm{g} / \mathrm{kg}) \dagger$} \\
\hline Dose 1 & $187 / 213$ & $88.9 \pm 20.3$ & $99.2(22.1-162.2)$ \\
\hline Dose 2 & $44 / 213$ & $53.8 \pm 21.5$ & $49.2(23.5-101.0)$ \\
\hline Dose 3 & $10 / 213$ & $51.6 \pm 24.0$ & $49.5(19.2-97.8)$ \\
\hline Dose 4 & $7 / 213$ & $56.0 \pm 21.4$ & $49.3(42.4-104.2)$ \\
\hline Dose 5 & $3 / 213$ & $47.5 \pm 4.5$ & $49.3(42.4-50.9)$ \\
\hline \multicolumn{4}{|l|}{ Infusion } \\
\hline Start time relative to CCU admission (h) & 213 & $23.9 \pm 141.6$ & $0.3(-15.6 \neq$ to 1799$)$ \\
\hline Duration during CCU stay $(\mathrm{h})$ & 213 & $86.7 \pm 118.4$ & $43.1(0.5-928.6)$ \\
\hline Average dose rate ( $\mu \mathrm{g} / \mathrm{kg}$ per minute) & 213 & $0.62 \pm 0.20$ & $0.64(0.13-2.08)$ \\
\hline Cumulative dose $(\mathrm{mg} / \mathrm{kg})$ & 213 & $3.52 \pm 5.63$ & $1.47(0.0167-40.63)$ \\
\hline Cumulative duration of interruptions & 213 & $12.0 \pm 96.2$ & $0(0-1244)$ \\
\hline Admissions with at least 1 interruption & 213 & $16(7.5)$ & \\
\hline No. of interruptions $\geq 15 \mathrm{~h}$ & 16 & $9(56)$ & \\
\hline No. of interruptions $<15 \mathrm{~h}$ & 16 & $7(44)$ & \\
\hline Tapering & 213 & & \\
\hline No & & $83(39.0)$ & \\
\hline Yes & & $70(32.9)$ & \\
\hline Unknown & & $60(28.2)$ & \\
\hline
\end{tabular}

$\overline{\mathrm{CCU}}=$ Critical Care Unit.

*Numerator $=$ number of admissions in which patients experienced event, denominator = number of admissions for which data were available.

tCalculation of mean and median loading doses excluded the 17 admissions with no loading dose. Loading doses may be administered in the operating room and/or the CCU, so some patients might have received doses in both locations. ¥Negative lower limit indicates that milrinone was initiated before admission to the CCU (i.e., in the operating room).

\section{DISCUSSION}

This retrospective study involved a cohort of 197 patients representing 213 admissions to the CCU over a 6-month period. The median initial loading dose was $99.2 \mu \mathrm{g} / \mathrm{kg}$, and the median infusion rate was $0.64 \mu \mathrm{g} / \mathrm{kg}$ per minute for a median duration of 43.1 hours. Milrinone duration was significantly associated with low cardiac output syndrome, but milrinone dosing was not significantly associated with adverse effects (arrhythmia or thrombocytopenia).

\section{Dosing of Milrinone}

For most of the admissions (92\%), the patients received a loading dose, usually (for $80.3 \%$ of admissions) before admission to the CCU (i.e., in the operating room). There was no apparent tapering of dose in two-thirds of the patients. Three major findings were observed regarding milrinone dosing.

First, initial loading doses (median $99.2 \mu \mathrm{g} / \mathrm{kg}$ ) exceeded the dose recommended in the literature $(50 \mu \mathrm{g} / \mathrm{kg})$, but infusion rates were within ranges studied in children $(0.2$ to $0.75 \mu \mathrm{g} / \mathrm{kg}$ per minute $)^{2,3,5,7-10}$ and adults $(0.375$ to $0.75 \mu \mathrm{g} / \mathrm{kg}$ per minute). ${ }^{20}$ Among the 196 admissions in which the patient received one or more loading doses, the initial loading dose was greater than $80 \mu \mathrm{g} / \mathrm{kg}$ for 134 (68.4\%); this value is almost twice the recommended loading dose for adults $(50 \mu \mathrm{g} / \mathrm{kg}){ }^{20}$ The data from pediatric studies are conflicting, with loading doses ranging from 50 to $135 \mu \mathrm{g} / \mathrm{kg}$. ${ }^{2,37,10}$ In the current study, initial loading doses were higher if given in the operating room. For adults with cardiopulmonary bypass, loading doses above the usual $50 \mu \mathrm{g} / \mathrm{kg}$ were needed to achieve therapeutic milrinone concentrations. ${ }^{21}$ Loading doses of $100 \mu \mathrm{g} / \mathrm{kg}$ and greater have been studied in neonates with cardiopulmonary bypass.

Second, repeat loading doses (median $49 \mu \mathrm{g} / \mathrm{kg}$ ) were common, which again raises the question of whether an optimal maintenance dosing regimen was being used. Taken with the high incidence of low cardiac output syndrome among patients who were receiving milrinone, these data suggest that dosing recommendations may require further evaluation.

Third, the milrinone dose was not adjusted for patients with renal impairment. The correlation between average dose rate and creatinine level was weak $\left(r^{2}<0.1\right.$ for all pediatric age groups; Figure 2). This is relevant because up to $85 \%$ of milrinone is eliminated renally, ${ }^{22}$ and for $34.9 \%$ of the admissions, the patient had a high creatinine level relative to age-defined normal ranges. The manufacturer recommends adjustment of the milrinone dosage for adults with severe renal impairment, ${ }^{20}$ and milrinone has a longer serum half-life and 

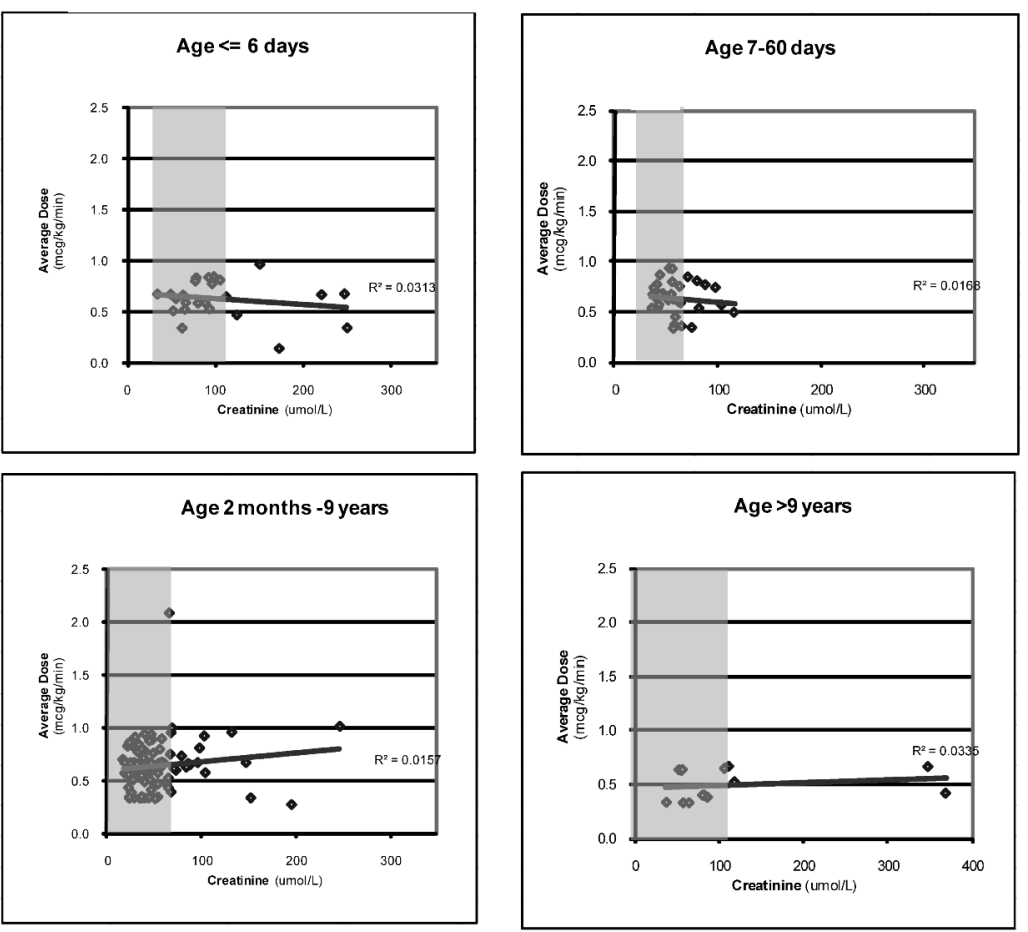

Figure 2. Average dose rate for milrinone as a function of maximum creatinine value, according to age-defined creatinine reference groups. The shaded area in each graph represents the normal creatinine range for the particular age group. For all age groups, average dose rate was weakly correlated with creatinine level $\left(r^{2} \leq 0.0335\right)$, which suggests that milrinone was not dosed differently for patients with renal impairment.

lower renal clearance in patients with renal impairment than in healthy patients. ${ }^{23}$ To date, no prospective studies have described the optimal dose adjustment for children with renal impairment.

\section{Association of Milrinone Dosing with Efficacy}

Despite the fact that for most admissions (80.3\%) the patient started milrinone before admission to the CCU, low cardiac output syndrome during the CCU stay was common (76.1\%). This frequency was nearly twice the $45 \%$ reported in the Prophylactic Intravenous Use of Milrinone after Cardiac Operation in Pediatrics (PRIMACORP) study. ${ }^{5}$ Both studies defined low cardiac output syndrome as $\mathrm{AVO}_{2}$ difference of $30 \%$ or more, but the PRIMACORP study also counted those with doubling of inotropes. We excluded the inotrope component of the definition, and many of the patients in our study were receiving additional inotropes. The observed mortality rate of $6.1 \%$ was well above that observed in the PRIMACORP study ( $0.8 \%$, with no deaths during milrinone therapy), which suggests that the population in the current study had a higher severity of illness.
The population in the current study differed in other respects from previous study populations. ${ }^{2,3,5,16}$ The age range was wider (from less than 1 day old to 18 years), and the patients had greater severity of illness and underwent more complex surgeries (including single-ventricle repair). This highlights the paucity of literature assessing milrinone use in an "expanded population" that includes patients with a single functional ventricle and children with septic shock.

There appeared to be a trend between milrinone therapy involving greater average infusion rate and longer duration and greater likelihood of low cardiac output syndrome (Table 3). This suggests that sicker patients may require more milrinone, although the retrospective nature of the study prevents more definitive conclusions on this point. The complexity of the patient population (e.g., patients with a single ventricle) may explain the duration of milrinone use (up to $928.6 \mathrm{~h}$ or nearly 39 days), although this cannot be confirmed. It was interesting that type of surgery (single-ventricle versus biventricular) was not significantly associated with low cardiac output syndrome in the regression model. There was a trend toward an association between $\mathrm{AVO}_{2}$ difference of $30 \%$ or more and a greater average dose rate of milrinone $(p=0.053)$ (Table 3). A lactate difference greater than $2 \mathrm{mmol} / \mathrm{L}$ was positively associated with 
Table 3. Results of Multiple Logistic Regression

\begin{tabular}{|c|c|c|}
\hline Variable & $\begin{array}{c}\text { Pearson Correlation } \\
\text { Coefficient }\end{array}$ & OR $(95 \% \mathrm{Cl})$ \\
\hline $\begin{array}{l}\text { Low cardiac output syndrome, } \\
\text { defined as } \mathrm{AVO}_{2} \geq \mathbf{3 0 \%}(\boldsymbol{n}=\mathbf{2 1 3}) \\
\text { Milrinone average dose rate } \\
\text { Dopamine dose } \\
\text { No. of nephrotoxins } \\
\text { Pacemaker use } \\
\text { Predicting outcome ( } C \text { index) } \\
\text { Hosmer-Lemeshow test }\end{array}$ & $\begin{array}{c}2.1053(p=0.053) \\
0.7238(p=0.012) \\
-0.4664(p=0.015) \\
2.0845(p=0.009) \\
0.752 \\
\chi^{2}=14.8, \mathrm{df}=8 \\
p=0.062\end{array}$ & $\begin{array}{ll}8.21 & (0.98-69.15) \\
2.06 & (1.18-3.61)^{\star} \\
0.63 & (0.43-0.91)^{\star} \\
8.04 & (1.67-38.68)^{\star}\end{array}$ \\
\hline $\begin{array}{l}\text { Low cardiac output syndrome, defined } \\
\text { as lactate difference }>\mathbf{2} \text { mmol/L }(\boldsymbol{n}=\mathbf{2 1 3}) \\
\text { Milrinone duration (cumulative) } \\
\text { Predicting outcome }(C \text { index) } \\
\text { Hosmer-Lemeshow test }\end{array}$ & $\begin{array}{c}0.0114(p<0.001) \\
0.890 \\
x^{2}=6.27, \mathrm{df}=8, p=0.61\end{array}$ & $1.01(1.01-1.02)^{*}$ \\
\hline $\begin{array}{l}\text { Arrhythmia }(\boldsymbol{n}=\mathbf{2 1 3}) \\
\text { Milrinone average dose rate } \\
\text { Dopamine dose } \\
\text { Phenoxybenzamine dose } \\
\text { Pacemaker use } \\
\text { Temperature on day } 1 \\
\text { Number of anti-arrhythmic drugs } \\
\text { Predicting outcome }(C \text { index }) \\
\text { Hosmer-Lemeshow test }\end{array}$ & $\begin{array}{c}1.1164(p=0.23) \\
0.7053(p=0.002) \\
-0.7601(p=0.13) \\
1.9665(p<0.001) \\
0.3349(p=0.040) \\
2.5286(p=0.001) \\
0.807 \\
x^{2}=2.71, \mathrm{df}=8 \\
p=0.95\end{array}$ & $\begin{aligned} 3.05 & (0.50-18.77) \\
2.02 & (1.29-3.18)^{\star} \\
0.47 & (0.18-1.24) \\
7.14 & (2.94-17.34)^{\star} \\
1.40 & (1.02-1.92)^{\star} \\
12.54 & (2.77-56.64)^{\star}\end{aligned}$ \\
\hline $\begin{array}{l}\text { Platelet count }<50 \times 10^{9} / \mathbf{L}(\boldsymbol{n}=\mathbf{2 1 3}) \\
\text { Milrinone loading dose (cumulative) } \\
\text { Length of stay } \\
\text { Dopamine dose } \\
\text { Phenoxybenzamine dose } \\
\text { Epinephrine dose } \\
\text { Predicting outcome (C index) } \\
\text { Hosmer-Lemeshow test }\end{array}$ & $\begin{array}{c}-0.00313(p=0.53) \\
0.0468(p=0.020) \\
1.0214 \quad(p=0.001) \\
1.3615(p=0.016) \\
1.0376(p=0.010) \\
0.937 \\
x^{2}=4.57, \mathrm{df}=8, \\
p=0.802\end{array}$ & $\begin{array}{l}0.997(0.987-1.007) \\
1.05(1.01-1.09)^{*} \\
2.78(1.50-5.14)^{*} \\
3.90(1.29-11.78)^{*} \\
2.82(1.28-6.24)^{*}\end{array}$ \\
\hline
\end{tabular}

$\mathrm{AVO}_{2}=$ difference in oxygen saturation between arterial and mixed venous blood, $\mathrm{df}=$ degrees of freedom.

${ }^{*} p<0.05$.

a longer duration of infusion $(p<0.001)$. However, the odds ratio was close to 1 , so the clinical significance is questionable, even though the result was statistically significant. Use of a pacemaker and dose of dopamine were positively associated with $\mathrm{AVO}_{2}$ difference of $30 \%$ or more (Table 3). These 2 factors may indicate the acuity of illness, with sicker patients having a greater likelihood of low cardiac output syndrome. The number of nephrotoxins was negatively associated with $\mathrm{AVO}_{2}$ difference or $30 \%$ or above. One explanation for this may be that antibiotics coded as nephrotoxins (i.e., aminoglycosides) were used for prophylaxis in cases of delayed sternal closure, and this delayed closure may have reduced the likelihood of low cardiac output syndrome. However, we did not determine the incidence of sternal opening, and this explanation remains purely speculative.

\section{Association of Milrinone Dosing Regimen with Adverse Effects}

Thrombocytopenia and arrhythmias are well documented adverse effects of milrinone. The reported incidence of throm- bocytopenia among children receiving milrinone has ranged from $10 \%$ to $58 \%{ }^{2,24}$ The extent of this range is partly due to the various methods of assessing platelet function and to confounders, such as cardiac surgery, that can also cause thrombocytopenia. Various types of arrhythmias have been documented in $6 \%$ to $29 \%$ of patients receiving milrinone. ${ }^{2,24,25}$

We found no statistically significant associations between milrinone dose and adverse effects. Adverse events were frequent (thrombocytopenia in $12.7 \%$ of admissions, arrhythmia in $38.5 \%)$. There was a trend toward greater likelihood of thrombocytopenia with greater milrinone loading doses, but this was neither statistically significant $(p=0.53)$ nor clinically significant (odds ratio 0.997) (Table 3). Determining the incidence of milrinone-induced thrombocytopenia might be difficult because of potential confounding factors in the intraoperative and postoperative periods. ${ }^{2}$

Regression analysis revealed a significant association between the adverse effects of milrinone and the following factors: need for inotropes, length of stay, use of a pacemaker, body temperature on day 1 of milrinone therapy, and number of anti-arrhythmic medications. This indicates the diversity of 
factors that could confound the incidence of arrhythmias and thrombocytopenia.

\section{Limitations}

This study had several limitations. The short time frame (6 months) did not allow analysis of temporal trends in milrinone use. The use of logistic regression, which focuses on the presence or absence of an event, prevented us from capturing the time course (i.e., onset, frequency, duration) of outcomes. The time course of independent variables was not analyzed, which may further limit the ability to establish a temporal relationship between changes in milrinone dosing and outcomes, including the ability to evaluate initial response to milrinone. Data collection was confined to the period during which milrinone was being administered, and it is therefore unknown whether patients had pre-existing low cardiac output syndrome, renal failure, and/or thrombocytopenia (i.e., before use of milrinone). We did not follow up on outcomes after milrinone was stopped, potentially missing important milrinonerelated outcomes that occurred after the drug was discontinued.

The results of this single-centre study may not reflect practice in other institutions.

The observational, retrospective nature of the data meant that we were unable to determine causality, i.e., whether the milrinone caused the adverse events described or if the milrinone prevented more severe low cardiac output syndrome. It was difficult to control for confounders that might predispose patients to low cardiac output syndrome, arrhythmias, or thrombocytopenia. Also, the reasons for changes in dose rate (e.g., adverse effects or lack of efficacy) were unknown. In addition, it was not possible to obtain milrinone serum concentrations for these patients; only the dose could be ascertained. Hypotension is likely multifactorial and fluctuates with the clinical status of a critically ill patient, so it was difficult to associate this potential adverse effect of milrinone with the specific dosing parameters. A prospective study would allow temporal association between development of hypotension and loading doses or accumulation of milrinone. Also, although the results of this study suggest that sicker patients require more milrinone, this is only a hypothesis; a prospective study design would be helpful in exploring severity of illness (e.g., type of cardiac lesion or repair) and dosing as predictors of outcome.

The use of a lactate difference of greater than $2 \mathrm{mmol} / \mathrm{L}$ and $\mathrm{AVO}_{2}$ difference of $30 \%$ or more as markers of low cardiac output syndrome had limitations. The incidence of these 2 measures was quite different: $76.1 \%$ of admissions with $\mathrm{AVO}_{2}$ difference of $30 \%$ or more and $15.3 \%$ of admissions with lactate difference greater than $2 \mathrm{mmol} / \mathrm{L}$ (Table 1). The PRIMACORP study similarly found that the incidence of $\mathrm{AVO}_{2}$ difference of $30 \%$ or more was greater than the incidence of metabolic acidosis (45.5\% versus 22.7\%). ${ }^{5}$ Thus, lactate difference may underdetect the incidence of low cardiac output syndrome. The $\mathrm{AVO}_{2}$ difference is thought to be the more sensitive marker in our study.
Using maximum creatinine levels as a marker for renal impairment has limitations, including the fact that elevations in creatinine lag behind renal insult. Creatinine clearance would have been preferable but was not measured for the patients studied here. Data on urine output and fluid balance were also collected, but these measures can be confounded by use of diuretics. Therefore, creatinine was the best available marker of renal function.

Finally, some patients were included more than once in our study (12 patients had 2 admissions, and 2 patients had 3 admissions). It is difficult to tell what impact these repeat patients had on the data, as they represented a minority $(7.1 \%)$ of the study population. Also, the condition of patients in the CCU tends to be unstable, and the same patient may have presented very differently during separate admissions.

\section{Implications for Practice}

This study highlights the paucity of information to guide optimal milrinone dosing for children, particularly in more complex cases (e.g., single ventricle, septic shock) and for patients with renal impairment. The results provide a basis for further pharmacokinetic and pharmacodynamic studies. One of the co-investigators on the current study (C.P.) is now working on a pilot prospective pharmacokinetic and pharmacodynamic study at another pediatric centre, based on issues identified here. In addition, results from this study have increased awareness among practitioners at The Hospital for Sick Children that duration of therapy for postoperative cardiac patients should be limited and that maximum doses should be de-escalated as soon as possible. In addition, along with other clinical practice improvement initiatives, milrinone is now being discontinued for selected postoperative cardiac patients (those who have undergone uncomplicated cardiac repair) after the initial loading dose given in the operating room.

\section{CONCLUSIONS}

This report of a retrospective cohort study has described the use of milrinone in critically ill pediatric patients in the CCU of The Hospital for Sick Children. Most of the patients had undergone cardiovascular surgery. The initial loading dose, usually given in the operating room, was greater than the recommended $50 \mu \mathrm{g} / \mathrm{kg}$. Maintenance infusion was not adjusted for renal impairment. Dose tapering and infusion interruptions did not occur for the majority of patients.

There was an association between the milrinone dosing regimen and outcomes. In particular, there appeared to be a significant association between average dose rate and duration of milrinone therapy and low cardiac output syndrome. A prospective pharmacokinetic and pharmacodynamic study of this drug is warranted to define the relationship between the efficacy and toxicity of the drug and its plasma concentrations. The results of this study support the suggestion that efficacy should be explored as an end point. Up to $78 \%$ of patients experienced low cardiac output syndrome while receiving 
milrinone, which raises the question of whether current dosing is adequate. A greater understanding of the concentrationefficacy relationship for milrinone is necessary to improve therapeutic outcomes. Children with renal impairment require further study because of the risks associated with milrinone use and the paucity of prospective dose-finding literature in this group.

\section{References}

1. Young RA, Ward A. Milrinone. A preliminary review of its pharmacological properties and therapeutic use. Drugs 1988;36(2):158-192.

2. Ramamoorthy C, Anderson GD, Williams GD, Lynn AM. Pharmacokinetics and side effects of milrinone in infants and children after open heart surgery. Anesth Analg 1998;86(2):283-289.

3. Bailey JM, Miller BE, Lu W, Tosone SR, Kanter KR, Tam VKH. The pharmacokinetics of milrinone in pediatric patients after cardiac surgery. Anesthesiology 1999;90(4):1012-1018.

4. Chu CC, Lin SM, New SH, Ting CK, Chow LH, Tsou MY, et al. Effect of milrinone on postbypass pulmonary hypertension in children after tetralogy of Fallot repair. J Chin Med Assoc (Taipei) 2000;63(4):294-300.

5. Hoffman TM, Wernovsky G, Atz AM, Kulik TJ, Nelson DP, Chang AC, et al. Efficacy and safety of milrinone in preventing low cardiac output syndrome in infants and children after corrective surgery for congenital heart disease. Circulation 2003;107(7):996-1002.

6. Carcillo JA, Fields AI. Clinical practice parameters for hemodynamic support of pediatric and neonatal patients in septic shock. Crit Care Med 2002;30(6):1365-1378.

7. Lindsay CA, Barton P, Lawless S, Kitchen L, Zorka A, Garcia J, et al. Pharmacokinetics and pharmacodynamics of milrinone lactate in pediatric patients with septic shock. J Pediatr 1998;132(2):329-334.

8. Barton P, Garcia J, Kouatli A, Kitchen L, Zorka A, Lindsay C, et al. Hemodynamic effects of IV milrinone lactate in pediatric patients with septic shock: a prospective, double-blinded, randomized, placebocontrolled, interventional study. Chest 1996;109(5):1302-1312.

9. Zuppa AF, Nicolson SC, Adamson PC, Wernovsky G, Mondick JT, Burnham N, et al. Population pharmacokinetics of milrinone in neonates with hypoplastic left heart syndrome undergoing stage I reconstruction. Anesth Analg 2006;102(4):1062-1069.

10. Paradisis M, Jiang X, McLachlan AJ, Evans N, Kluckow M, Osborn D. Population pharmacokinetics and dosing regimen design of milrinone in preterm infants. Arch Dis Child Fetal Neonatal Ed 2007;92(3):F204-F209.

11. De Hert SG, Moens MM, Jorens PG, Delrue GL, DePaep RJ, Vermeyen KM. Comparison of two different loading doses of milrinone for weaning from cardiopulmonary bypass. J Cardiothorac Vasc Anesth 1995;9(3): 264-271.

12. Baer $\mathrm{AB}$, Holstege CP. Milrinone overdose induced hypotension reversed by vasopressin and norepinephrine infusions [abstract]. J Toxicol Clin Toxicol 2002;40(5):690.

13. Edelson J, Stroshane R, Benziger DP, Cody R, Benotti J, Hood WB Jr, et al. Pharmacokinetics of the bipyridines amrinone and milrinone. Circulation 1986;73(3 Pt 2):III145-III152

14. Benotti JR, Lesko LJ, McCue JE, Alpert JS. Pharmacokinetics and pharmacodynamics of milrinone in chronic congestive heart failure. $\mathrm{Am} \mathrm{J}$ Cardiol 1985;56(10):685-689.

15. Woolfrey SG, Hegbrant J, Thysell H, Fox PA, Lendrem DW, Lockwood GF, et al. Dose regimen adjustment for milrinone in congestive heart failure patients with moderate and severe renal failure. J Pharm Pharmacol 1995; 47(8):651-655.

16. Bailey JM, Hoffman TM, Wessel DL, Nelson DP, Atz AM, Chang AC, et al. A population pharmacokinetic analysis of milrinone in pediatric patients after cardiac surgery. J Pharmacokinet Pharmacodyn 2004; 31(1):43-59.

17. Leteurtre S, Martinot A, Duhamel A, Proulx F, Grandbastien B, Cotting $\mathrm{J}$, et al. Validation of the paediatric logistic organ dysfunction (PELOD) score: prospective, observational, multicentre study. Lancet 2003;362(9379):192-197.

18. Manor-Shulman O, Beyene J, Frndova H, Parshuram CS. Quantifying the volume of documented clinical information in critical illness. J Crit Care 2008;23(2):245-150.

19. Kleinbaum, DG, Kupper LL. Applied regression analysis and other multivariable methods. North Scituate (MA): Duxbury Press; 1988.

20. McEvoy G, editor. AHFS drug information ${ }^{\oplus}$ 2005. Bethesda (MD): American Society of Health-System Pharmacists; 2005 [cited 2005 Jun 3]. Available from: http://online.statref.com/document.aspx?fxid=1\&docid $=414$ [registration required to access content].

21. Bailey JM, Levy JH, Kikura M, Szlam F, Hug CC Jr. Pharmacokinetics of intravenous milrinone in patients undergoing cardiac surgery. Anesthesiology 1994;81(3):616-622.

22. Sims C. Resuscitation agents. In: Bissonnette B, Dalens B, editors. Pediatric anesthesia. Principles and practice. New York (NY): McGraw Hill Co; 2002. p. 367-388.

23. Singlas E, Fillastre JP. Pharmacokinetics of newer drugs in patients with renal impairment (part II). Clin Pharmacokinet 1991;20(5):389-410.

24. Watson S, Christian K, Churchwell K. Use of milrinone in the pediatric critical care unit. Pediatrics 1999;104(3):1907-1914.

25. Tisdale JE, Patel R, Webb CR, Borzak S, Zarowitz BJ. Electrophysiologic and proarrhythmic effects of intravenous inotropic agents. Prog Cardiovasc Dis 1995;38(2):167-180.

Teresa Bishara, BSCPhm, RPh, ACPR, is a Staff Pharmacist with the Department of Pharmacy, North York General Hospital, Toronto, Ontario.

Winnie T W Seto, PharmD, MSc, is the Therapeutic Drug Monitoring Coordinator and Critical Care Pharmacist with the Department of Pharmacy, The Hospital for Sick Children, Toronto, Ontario.

Angela Trope, MSc, is a Critical Care Pharmacist with the Department of Pharmacy, The Hospital for Sick Children, Toronto, Ontario.

Christopher S Parshuram, MBChB, DPhil, is a Staff Physician with the Department of Critical Care Medicine, The Hospital for Sick Children, and Scientist in the department of Child Health Evaluative Sciences, The Hospital for Sick Children and University of Toronto, Toronto, Ontario. $\mathrm{He}$ is also affiliated with the Center for Safety Research and the Research Institute, The Hospital for Sick Children.

\section{Address correspondence to:}

Dr Winnie T W Seto

Therapeutic Drug Monitoring Coordinator

The Hospital for Sick Children

555 University Avenue

Toronto ON M5S $1 \times 8$

e-mail: winnie.seto@sickkids.ca

\section{Acknowledgments}

We acknowledge the following staff at The Hospital for Sick Children: Brian P Kavanagh, staff physician, Department of Critical Care Medicine, for his guidance during the study proposal phase; Joel A Kirsh, staff cardiologist, Division of Cardiology, for assessing the occurrence and type of arrhythmias; Gina Lee, database technician, Department of Critical Care Medicine, for technical assistance; Cecilia Hyslop, nurse educator, Cardiac Critical Care Unit, for invaluable advice; Christopher Caldarone, staff surgeon, Division of Cardiovascular Surgery, for reviewing the manuscript before submission; the Residency Advisory Committee, Department of Pharmacy, for advice on the study proposal; and Beverley Hales, Director of the Department of Pharmacy, for financial support (through the internal departmental research and educational fund) and advice on the manuscript. 